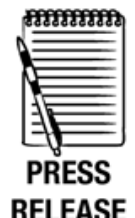

Emergency Department, Bristol Royal Infirmary, University Hospitals Bristol NHS Foundation Trust, Bristol, UK

\section{Correspondence to}

Rebecca Hoskins, Academic Department of Emergency Care, Emergency Department, Bristol Royal Infirmary, University Hospitals Bristol NHS Foundation Trust, Bristol BS2 8HW, UK; rebecca.hoskins@ uhbristol.nhs.uk

Accepted 15 March 2012

\title{
What is the burden of alcohol-related injuries in an inner city emergency department?
}

\author{
Rebecca Hoskins, Jonathan Benger
}

\begin{abstract}
Background The annual cost to the NHS of alcoholrelated injury and illness is estimated to be $£ 2.7$ billion. Alcohol-related violence has become a concerning public health issue. This study set out to establish the burden of alcohol-related violence in an inner city UK emergency department (ED).
\end{abstract}

Methods This single centre study was undertaken in the ED of the Bristol Royal Infirmary. This department serves an inner city population. An independent researcher administered a questionnaire to every patient who attended during the study period. A questionnaire was also administered to the treating clinician to ascertain the diagnosis, and whether the patient's attendance was related to alcohol use.

Results $14 \%(n=111)$ of participants felt that their attendance at the ED was related to alcohol. 11\% of all injured patients felt it was due to alcohol consumption. $3 \%$ of patients attended with an alcohol-related illness. The treating clinicians reported that $21 \%$ of all patients in this study attended with a problem either directly or indirectly attributable to alcohol.

Discussion The number of attendances attributable to alcohol-related injury and illness was at least $14 \%$ of all patients. One third of patients presenting with an alcohol-related illness or injury required admission to hospital. If these figures are extrapolated, the number of patients presenting with alcohol-related injury is in excess of 7000 attendances to the Bristol Royal Infirmary annually, or nearly 2 million ED patients every year in England and Wales, resulting in 640000 admissions.

The total cost to the NHS of alcohol-related injuries and illnesses is estimated to be $£ 2.7$ billion a year, ${ }^{1}{ }^{2}$ with alcohol-related crime, assaults and disorder costing a further $£ 7.3$ billon. $^{3}$ Alcohol-related harm is estimated to cost society between $£ 17.7$ billion and $£ 25.1$ billion per year. ${ }^{4}$ In a recent study Benger and Carter ${ }^{5}$ found that accidents and assaults were the most common cause of alcohol-related attendance to the emergency department (ED). Alcoholrelated violence has become a concerning public health issue. ${ }^{67}$ Hazardous drinking has been defined as the regular consumption of over 5 units a day for men and over 3 units a day for women. ${ }^{8}$ Uncontrolled drinking leads to public disorder, violence and long-term health problems. Recent research has suggested a sharp increase in harmful and hazardous drinking patterns amongst young adults, and the Chief Medical Officer has warned that Britain's 'binge drinking culture' is damaging greater numbers of young people than ever before. ${ }^{9}$

Cherpitel et al ${ }^{10}$ suggested that up to $46 \%$ of patients with injuries presenting to ED worldwide are alcohol-related. The British Crime Survey 2008-9 found that a similar percentage (47\%) of all violent incidents were alcohol-related. ${ }^{11}$ While Boyle et $a l^{12}$ found that $15 \%$ of patients attending their Emergency Department in key hours during a weekend period had suffered an alcohol-related problem. Nationally, various attempts have been made to control alcohol-related violence. However, a large proportion of alcohol-related assaults and alcohol-related violent incidents that result in patients attending ED are not reported to the police, ${ }^{1314}$ and thus the true extent of the problem is unknown.

Benger and Carter $^{5}$ demonstrated that sharing information relating to alcohol-related assaults with the police brought about positive changes with the potential to reduce the number of patients attending the ED. However, that study also demonstrated the difficulty of gaining an accurate estimate of the number of patients involved, despite employing a dedicated researcher. Compliance from staff in collecting data was variable, and led the researchers to conclude that the only way to improve data collection further would be to have a dedicated researcher working in the ED $24 \mathrm{~h}$ a day.

In the most deprived communities, increased alcohol consumption affects health outcomes in terms both of months of life lost and of alcoholspecific mortality. ${ }^{1}$ A strong link with deprivation has been found when looking at deaths attributable to alcohol. One of the key targets of the Department of Health's report 'Equality impact assessment-health inequalities: progress and next steps $^{\text {'15 }}$ is 'intervention and advice to reduce alcohol consumption and alcohol-related admissions'. Approximately $26 \%$ of adults in England are drinking at hazardous, harmful or dependent levels. The largest increase in the number of NHS alcoholrelated admissions is in the 35-49-year-old age group. Alcoholic liver disease, toxic effects of alcohol on mental and behavioural disorders due to alcohol have been identified as a primary or secondary diagnosis in this group of patients. ${ }^{1}$

Alcohol has a serious effect on behaviour and relationships in the home, affecting the mental health and behaviour of children of alcohol-misusing parents. ${ }^{16}$ It is also linked to psychiatric morbidity including depression. A third of domestic violence incidents have been linked to alcohol misuse. ${ }^{17}$ It is estimated that 1 million children live in families in which at least one parent misuses alcohol. ${ }^{17}$

The draft strategic framework for improving health in the southwest from 2008-9 to 2010-11 finds that in the population of the southwest of England, there are above national average levels of binge-drinking in men. One of the key performance 
targets of the document is to "halt the rise in hospital admissions for alcohol-related harm and achieve a downward trend by 2013'.

This study set out to understand the extent of the burden of alcohol-related violence in an ED, and to quantify the problem utilising a successful model of 24 -h recruitment used previously in research relating to illegal drug use. ${ }^{18}$

The objectives of this study were:

- To quantify the number of patient attendances to the ED of the Bristol Royal Infirmary that are attributable to alcoholrelated injury.

- To quantify the number of patient attendances to the ED of the Bristol Royal Infirmary that are attributable to alcoholrelated illness.

- To compare the perceptions of patients and clinicians in the contribution of alcohol regarding their visit to the Emergency Department.

\section{METHODS}

This single centre study was undertaken in the level 1 ED of the Bristol Royal Infirmary, part of the University Hospitals Bristol NHS Foundation Trust. This department sees adult patients (16 years and older) only, and serves an inner city population, which includes the city centre, which has a large number of pubs, nightclubs and bars. The annual patient attendance to the ED is approximately 62000 new adult patients per annum. The study began in June 2009 and took place over a period of 4 weeks. The aim was to collect data over a 'typical 168-h week' by dividing the week into $14 \times 12 \mathrm{~h}$ periods over the course of 4 weeks in order to allow a single researcher to cover all of the necessary times (see table 1).

\section{Patient questionnaires}

An independent researcher, employed specifically to collect data for this study, introduced themselves to all patients who attended the ED during the study recruitment periods. The researcher made it clear that there was no obligation to take part in the survey, and that the answers given were anonymous and would not be seen by the treating clinicians.

A questionnaire was then verbally administered to all willing participants. This collected baseline data; it also asked the patient whether they had been drinking alcohol, before going on to ask about average weekly alcohol consumption. A laminated card with pictures of alcoholic drinks and standard units was shown to patients to assist in estimating their alcohol consumption. Finally, injured patients were asked whether they felt that their injury had been received from someone else who had been drinking, or if they felt that they had received the injury because they themselves had been drinking alcohol.

It was important to ensure anonymity for patients taking part in the study, but still allow the independent researcher to keep track of who had been approached. This was achieved by the researcher identifying the patient from the last two digits of their ED number. The ED number is an eight digit number

Table 1 Typical 168-h week over which the data were collected

\begin{tabular}{ll}
\hline Sunday in June 2009 08:00-20:00 & Sunday in June 2009 20:00-08:00 \\
Monday in June 2009 08:00-20:00 & Monday in June 2009 20:00-08:00 \\
Tuesday in June 2009 08:00-20:00 & Tuesday in June 2009 20:00-08:00 \\
Wednesday in June 2009 08:00-20:00 & Wednesday in June 2009 20:00-08:00 \\
Thursday in June 2009 08:00-20:00 & Thursday in June 2009 20:00-08:00 \\
Friday in June 2009 08:00-20:00 & Friday in June 2009 20:00-08:00 \\
Saturday in June 2009 08:00-20:00 & Saturday in June 2009 20:00-08:00 \\
\hline
\end{tabular}

assigned to the attendance that increases by one with each new patient. Using the last two digits allowed the researcher to identify the patient on the day of attendance but not beyond this because the last two digits are repeated every 100 patients. Using this identification system meant that the confidentiality and anonymity of the patient was assured.

\section{Clinician questionnaires}

A questionnaire was also administered to the treating clinician to ascertain what the most likely diagnosis was, and whether the doctor or other clinician (emergency nurse practitioner or extended scope physiotherapist) who saw the patient felt that the patient's attendance was related to alcohol use. The clinician was asked to identify whether the patient's attendance was:

- Directly related to alcohol consumption (an injury or alcoholrelated illness).

- Indirectly related to alcohol consumption (the assailant may have been drinking, the patient presented with an illness that may be related to alcohol ingestion such as pancreatitis, or the patient presented with self-harm following alcohol ingestion)

- Unrelated to alcohol consumption.

For injured patients the clinician was also asked for their opinion as to whether the patient was the assailant, the victim or this was not applicable.

\section{Inclusion and exclusion criteria}

The inclusion criteria were:

- All patients attending the ED during the study recruitment periods with the exception of patients for whom an interview was felt to be inappropriate, insensitive or fitted the exclusion criteria.

The exclusion criteria were:

- Potentially life-threatening illness or injury (triage category 1).

- Non-English speaking.

- Patients with chronic mental impairment (such as dementia).

- Patients less than 16 years old.

- Patients who were severely emotionally upset.

- Patients declining to participate.

- Patients known to the researcher.

\section{Ethical issues}

The NHS research governance framework was used throughout the study. This included the provision of informed consent, voluntary participation, confidentiality and anonymity. Ethics committee approval was obtained from the North Somerset and South Bristol NHS Research Ethics Committee. Patients who requested help with alcohol-related issues were offered an appointment with an alcohol clinical nurse specialist who was based within the ED.

\section{RESULTS \\ Patient participants}

The reasons for being excluded from the study are shown in table 2.

The mean age of the participants was 41 years (range 16-96 years) (figure 1 ).

Overall, $19 \%(n=149)$ of patients reported that they had consumed alcohol on the day of their attendance to the ED; estimates of the number of units consumed that day ranged from 0.5 to 50 units (ie, during that calendar day rather than the preceding 24 hours). The mean number of alcohol units consumed that day was 10.6. The highest percentage of patients who had consumed alcohol before their attendance was found in 
Table 2 Reasons for patients being excluded from the study

\begin{tabular}{|c|c|c|c|c|c|c|c|c|}
\hline Too unwell & Severely emotionally upset & Non-English speaking & Mental incapacity & Known by researcher & Already seen that day & Aggressive & Absconded & Total \\
\hline 39 & 30 & 22 & 14 & 7 & 7 & 4 & 2 & 125 \\
\hline
\end{tabular}

patients attending on a Friday night (48\%) and Saturday night (39\%) (figure 2).

Nineteen per cent $(n=146)$ of all participants reported drinking more than 21 units of alcohol each week. Thirty-four per cent of all participants $(n=259)$ told the independent researcher that they did not consume alcohol.

\section{Findings from the patients with alcohol-related attendances}

Fourteen per cent $(n=111)$ of participants felt that their attendance at the ED was related to alcohol, and 87 of these $(11 \%$ of all participants) presented with an injury.

Of the 87 patients with an alcohol-related injury, 48 (55\%) believed that they had received their injury from someone who had been drinking.

Patients who presented with an alcohol-related injury were asked to estimate how many units of alcohol they drank on average each week. Fifty-four per cent of this group reported that they consumed more than the maximum recommended weekly units, while $34 \%$ reported drinking no alcohol on a weekly basis.

\section{Clinicians}

Clinical staff (doctors, emergency nurse practitioners and extended scope physiotherapists) completed 640 questionnaires relating to the participant group. Twenty-one per cent of patient attendances for which a questionnaire was completed $(n=131)$ were thought to be directly $(88 / 640,14 \%)$ or indirectly $(43 / 640$, $7 \%)$ related to alcohol consumption. Six per cent $(n=40)$ of all patients for whom a questionnaire was completed were thought to have been the victim of alcohol-related violence, while $2 \%$ $(n=13)$ were thought to have been the assailant. Therefore, the clinicians' view was that $8 \%$ of all attendances at the $\mathrm{ED}$ during the study period were due to alcohol-related violence.

\section{Hospital admissions}

Thirty-six of the 111 patients presenting with an alcohol-related illness or injury (32\%) were admitted to hospital. Of these, 19 patients were admitted to the ED observation unit, 10 to an acute medical ward, four to a surgical ward and three to an orthopaedic ward. All of the patients admitted to a medical ward were admitted with a diagnosis of upper gastrointestinal bleeding secondary to alcohol consumption, and all of the

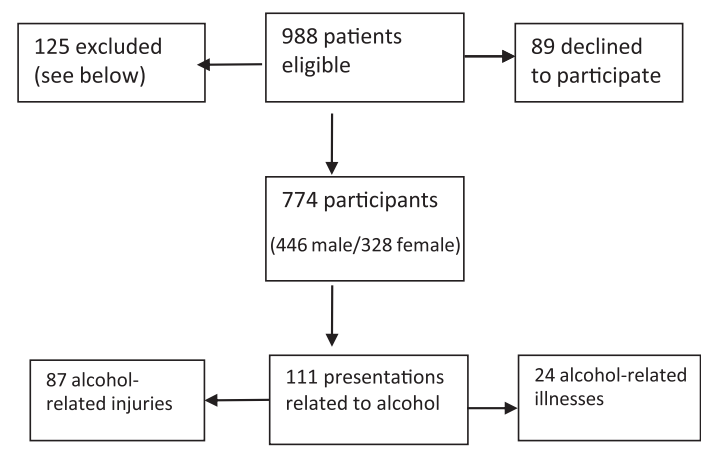

Figure 1 Patient flow through the study. patients admitted to a surgical ward were admitted with pancreatitis secondary to alcohol consumption. Forty-one per cent $(22 / 53)$ of all patients who had attended as a result of alcohol-related violence were admitted to hospital. The majority of these were admitted to the observation unit. It is noteworthy that no admissions were related to alcohol withdrawal, this finding may have been in part due to the active approach and partnership model taken by the inpatient hepatology teams, alcohol specialist nurse team within this hospital and specialist alcohol services within the local mental health trust.

\section{DISCUSSION}

Harmful and hazardous alcohol use is a major problem. Harmful drinking is defined as a pattern of drinking that is already causing damage to health, to either physical or mental health. ${ }^{6}$ Hazardous drinking has been defined as the regular consumption of over five units a day for men and over three units a day for women. ${ }^{16}$ Uncontrolled drinking leads to public disorder, violence and long-term health problems. Recent research has suggested a sharp increase in harmful and hazardous drinking patterns among young adults, and the Chief Medical Officer has warned that Britain's 'binge drinking culture' is damaging greater numbers of young people than ever before. ${ }^{19}$

\section{The burden of alcohol-related injuries}

The main purpose of this study was to identify the burden placed on our ED and acute hospital trust by patient attendances related to alcohol. Our results show that over a typical 168 -h week $14 \%$ of all patient attendances were attributable to alcohol, of which the vast majority were due to alcohol-related injury. If these figures are extrapolated, the number of patients presenting with alcohol-related injury is in excess of 7000 attendances to the Bristol Royal Infirmary annually, or nearly 2 million patients every year in England and Wales. However, extrapolation of this figure beyond the Bristol Royal Infirmary should be treated with caution because this study was conducted in an inner city hospital, and other parts of the country may have significantly different rates of alcohol-related ED attendance.

\section{Patient recruitment}

Recruitment of patients attending the ED is known to be challenging, ${ }^{20}$ and we were therefore satisfied that $78 \%$ of eligible patients were included in the study. We attribute this to

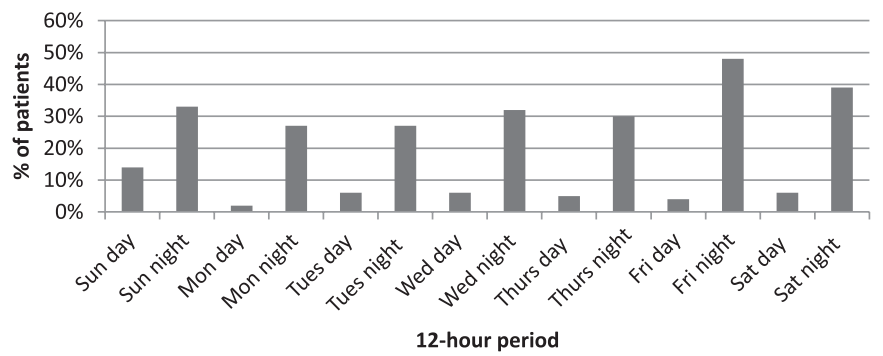

Figure 2 Percentage of patients reporting alcohol consumption on the day of their emergency department attendance. 
the study design and the personal qualities of the independent researcher who administered the questionnaire. However, 988 eligible patients is somewhat less than the 1170 that we would expect to see in an average week, given our annual attendance of approximately 62000 patients. June is a summer month, and the ED tends to have fewer patient attendances than in the winter, but despite this it is likely that our study design led to up to 185 patients being missed, particularly at the start and finish of recruitment periods.

The commonest reasons for study exclusion were extreme distress and potentially life-threatening illness/injury, and it is unclear what effect the inclusion of these patients would have had on the overall results, although previous work ${ }^{8}$ demonstrated that $15 \%$ of patients treated in the resuscitation room had a positive blood alcohol concentration when measured, and consequently were found to have a higher rate of re-attendance in the following 6 months. It is impossible to comment in any detail on the patients who declined to participate, although it seems plausible that this group would include both those who never drink, and therefore might not see the study as relevant, and those who are heavy drinkers and may have chosen not to discuss this with the researcher.

\section{Patient characteristics}

As expected, patients attending the ED as a result of alcohol consumption were more likely to be young men, usually in the 16-25-year age group and with a ratio of three men to one woman. There was a marked peak in alcohol-related attendances on Friday and Saturday nights, reflecting the findings of Drummond et al. ${ }^{21}$ The observation that some patients presenting with an alcohol-related injury reported no regular alcohol consumption may be explained by their view that they had been assaulted by a person under the influence of alcohol, or it may be the case that they drink alcohol only very occasionally, or had decided to do so in response to a specific life stress or crisis.

Unsurprisingly, the majority of patients who were a victim of alcohol-related violence presented with a head or facial injury. Magennis et al ${ }^{22}$ estimated that 125000 people in Britain have a facial injury as a result of assault annually, and that in the majority of cases the patient or assailant will have consumed alcohol.

\section{Alcohol-related hospital admissions}

In 2007/8 863300 alcohol-related admissions were recorded in the UK; a $69 \%$ increase from $2002 / 3{ }^{23}$ In our study the admission rate following an ED attendance with alcohol-related illness or injury was $32 \%$ (36/111), which if extrapolated would equate to 640000 hospital admissions every year in England and Wales, close to the officially recorded figure noted above.

\section{Alcohol consumption}

It is estimated that approximately $26 \%$ of adults in England are drinking at hazardous, harmful or dependent levels. ${ }^{15}$ In this study, $54 \%$ of the patients who presented with an alcoholrelated injury reported drinking more than 21 units of alcohol each week. This suggests that the majority of participants in this group demonstrated increasing-risk drinking; that is, regularly consuming between 22 and 50 units per week for men and 15-35 units for women as well as demonstrating hazardous drinking habits (regular consumption of over five units a day for men and over three units a day for women). ${ }^{19} 24-26$ This level of drinking is associated with alcoholic liver disease, an increased risk of certain cancers as well as an increase in mental and behavioural disorders. ${ }^{15}$

\section{Clinician perceptions}

The view of participating clinicians was that $21 \%$ of patients attending the ED during the study period had a presenting complaint that was either directly or indirectly related to alcohol, and that $8 \%$ of all ED attendances were attributable to alcohol-related violence.

The clinicians reported that $14 \%$ of patient attendances were directly related to alcohol, which agreed exactly with the patient sample. However, the clinicians reported a further $7 \%$ of attendances as being indirectly related to alcohol. It is not clear whether patients were less likely to accept the role of alcohol in their attendance, or whether they failed to appreciate the indirect consequences of alcohol consumption. This is the first time to our knowledge that patients and clinicians perceptions in this area have been specifically explored within a study.

Clinician estimates of the frequency of alcohol-related presentation consistently exceeded patient estimates. Interestingly, Huntley et $\mathrm{al}^{27}$ found that over two thirds of the junior doctors participating in their study admitted to misusing alcohol once a month, suggesting that personal experience as well as professional experience may cause healthcare professionals potentially to overestimate patient intoxication. ${ }^{28}$ In our study only $83 \%$ of participants had a clinician questionnaire completed. As a result it would appear that the true rate of alcohol-related ED attendance lies somewhere between the patient and clinician estimates of $14 \%$ and $21 \%$.

The clinician view as to whether a particular patient involved in alcohol-related violence was likely to have been a victim or assailant should also be treated with considerable caution, and indeed the two roles can blur at times.

\section{Brief intervention}

The Bristol Royal Infirmary is fortunate in being one of only $17 \%$ of ED nationally that has access to a specialist alcohol worker. ${ }^{29}$ The evidence presented so far shows that people who consume alcohol in hazardous or harmful amounts are more likely to require the help of the emergency services, ED, and admission to hospital with an alcohol-related injury or illness. They also require help from mental health services, as well as outpatient services for follow-up and ongoing care related to alcohol-related illness. Their behaviour may require police or social services involvement and the link to domestic violence incidents can involve partners, children and young people and social services.

Crawford et $a l^{9}$ demonstrated that for every two ED patients who were referred for a brief intervention there is a consequent reduction of one re-attendance per year to the ED. All patients attending this department are now screened using the Paddington alcohol tool and anyone found to be 'positive' are offered a referral to the alcohol nurse specialist for a brief or extended intervention.

\section{Study limitations}

The most obvious limitation is the single site design, and while the findings can inform the future planning of public health services for the local population, they should be generalised to a wider population with considerable caution. It could be argued that the season in which this study was carried out could have had an impact on the numbers of patients attending with an alcohol-related problem. It could also be argued that asking patients to estimate their alcohol consumption on the day of attendance is not a validated measure.

There is also an issue associated with incomplete data, in that up to 185 patients were not approached or assessed to ascertain 
whether they met the study's inclusion criteria. While the model of employing a dedicated researcher to approach patients individually works well, particularly when asking questions about a patient's drug or alcohol consumption, the results are entirely reliant on the perceptions of the patient, the information they choose to disclose to the independent researcher and the veracity of that information.

\section{Future research and service development}

The findings of this study and previous studies in this field suggest that ongoing data collection within all Emergency Departments in the UK would give an important epidemiological perspective of the consequences of harmful and hazardous drinking to public health policy makers as well as the alcohol industry. Continuous data collection in ED would identify trends in alcohol-related presentations and demonstrate the effect of any local and national changes, for example, in alcohol unit labelling or minimum pricing. The challenge is developing processes that can collect these data with minimum additional burden on staff. This will ensure that accurate and consistent data are collected, and can be used by commissioners of health and social care to inform future commissioning decisions accurately in this area, with the aim of reducing the harmful consequences of drinking as well as a reduction in the burden of healthcare costs for ED and hospitals throughout the UK.

The introduction and evaluation of the impact of brief intervention services and alcohol specialist workers within ED is an important and valuable area for future research and service evaluation.

\section{CONCLUSION}

Extrapolation of these findings suggests that almost 7000 attendances each year at the Bristol Royal Infirmary ED are due to alcohol-related injury or illness. This equates to nearly 2 million patients annually in England and Wales.

It is worthy of note that in this study one third (32\%) of patients presenting with an alcohol-related illness or injury required admission to hospital. Furthermore, 54\% of patients who presented with an alcohol-related injury reported drinking more than 21 units of alcohol each week. This suggests that the majority of patients injured as a result of alcohol are hazardous drinkers, and that they incur high healthcare costs.

Acknowledgements The authors would like to thank the independent researcher, Judy Harrison, who collected the data, and also all the clinical staff in the ED of the Bristol Royal Infirmary who took part in this study.

Contributors $\mathrm{RH}$ designed the data collection tools. Both authors analysed the data. $\mathrm{RH}$ drafted and revised the paper, and is the guarantor. JB revised the paper.

Funding This study was supported by NHS Bristol, South Plaza, Marlborough Street, Bristol BS1 3NX, UK.

Competing interests None.

Patient consent Obtained.

Ethics approval Ethics approval was provided by North Somerset and South Bristol NHS Research Ethics Committee.

Provenance and peer review Not commissioned; externally peer reviewed.

\section{REFERENCES}

1. Department of Health Improvement Analytical Team. The Cost of Alcohol Harm to the NHS in England: An Update to the Cabinet Office (2003) Study. London: DH, 2008. http://www.parliament.uk/deposits/depositedpapers/2008/DEP2008-2703.pdf (accessed).

2. Department of Health. Reducing Alcohol Harm: Health Services in England for Alcohol Misuse. London: National Audit Office, 2009. http://www.publications. parliament.uk/pa/cm200809/cmselect/cmpubacc/925/925.pdf laccessed $15 \mathrm{Jul}$ 2011).

3. Cabinet Office, Prime Ministers Strategy Unit. Alcohol harm reduction Strategy for England. London: Cabinet Office, 2004. http://www.newcastle-staffs.gov.uk/ documents/community\%20and\%20living/community\%20safety/caboffce $\%$ 20alcoholhar\%20pdf.pdf (accessed 15 Jul 2011).

4. Department of Health. Safe, Sensible, Social- Consultation On Further Action London: DH, 2008. http://www.dhcarenetworks.org.uk/ library/Resources/ALC/ OtherOrganisation/Safe Sensible Social Consultation Review.pdf laccessed 2 Sep 2011)

5. Benger JR, Carter R. Could inter-agency working reduce emergency department attendances due to alcohol consumption? Emerg Med J 2008;25:331-4.

6. Baune BT, Mikolajczyk R, Reymann G, et al. A 6-months assessment of the alcoholrelated clinical burden at emergency rooms in 11 acute care hospitals of an urban area in Germany. BMC Health Serv Res 2005;5:73.

7. Charbonney E, McFarlan A, Haas B, et al. Alcohol, drugs and trauma: consequences, screening and intervention in. Trauma 2009;12:5-12.

8. Touqet R, Csipke E, Holloway $P$, et al. Resuscitation room blood alcohol concentrations: one-year cohort study. Emerg Med J 2008;25:752-6.

9. Crawford MJ, Patton R, Touquet R, et al. Screening and referral for brief intervention of alcohol-misusing patients in an emergency department: a pragmatic randomised controlled trial. Lancet 2004;364:1334-9.

10. Cherpital CJ, Ye T, Bond J, et al. Multi-level analysis of alcohol related injury among emergency department patients: a cross national study. Addiction 2005; 100:1840-50.

11. Home Office. Alcohol Related Crime. 2010. http://www.homeoffice.gov.uk/crimevictims/reducingcrime/alcoholrelatedcrime (accessed 27 May 2010).

12. Boyle A, Wee N, Harris R, et al. Alcohol-retlated emergency department attendances: is preloading a risk factor? Cross - sectional survey. International Journal Emergency Medicine 2010;3:151-5.

13. Shapland $\mathbf{M}$, Scully $\mathbf{C}$. Recording by the police of violent offences: an accident and emergency department perspective. Med Sci Law 1989;29:251-7.

14. Dawood M. Alcohol-related presentations in the emergency department. Nurs Stand 2008;22:50-6.

15. Department of Health. Equality Impact Assessment-Health Inequalities: Progress and Next Steps. London: DH, 2008. http://www.dh.gov.uk/en/Publication sandstatistics/Publications/PublicationsPolicyAndGuidance/DH_085307 laccessed 27 May 2010).

16. SIGN. The Management of Harmful Drinking and Alcohol Dependence in Primary Care. Guideline 74. 2004. http://www.sign.ac.uk/guidelines/fulltext/74/section1.htm (accessed 2 Sep 2011).

17. Alcohol Concern. Hidden Harm for Professionals Working with Parents Who Misuse Alcohol. Alcohol Concern, London: 2006. http://www.alcoholandfamilies.org.uk/ briefings/13.4.pdf (accessed 2 Sep 2011).

18. Binks S, Hoskins R, Salmon D, et al. Prevalence and healthcare burden of illegal drug use among emergency department patients. Emerg Med J 2005; 22:872-3

19. National Audit Office, DOH. 'Reducing Alcohol Harm: Health Services in England for Alcohol Misuse', http://www.nao.org.uk/publications/0708/reducing alcohol harm.aspx?alreadysearchfor=yes (accessed 2 Sep 2011).

20. Kendrick D, Lyons R, Christie N, et al. Recruiting participants for injury studies in emergency departments. Inj Prev 2007;13:75-7.

21. Drummond C, Phillips T, Coulton S, et al. National prevalence survey of alcoholrelated attendances at accident and emergency departments in England. Alcoholism Clini Exp Res 2005;29:6A

22. Magennis $\mathbf{P}$, Shepherd J, Hutchison I, et al. Trends in facial injury. BMJ 1998;316:325-6.

23. The NHS Information Centre. Statistics on Alcohol: England. Leeds: The Health \& Social Care Information Centre, 2009. http://www.ic.nhs.uk/webfiles/publications/ alcoholeng2009/Final\%20Format\%20draft\%202009\%20v7.pdf laccessed $15 \mathrm{Jul}$ 2011).

24. NICE public health guidance 23. Alcohol use Disorders: Preventing the Development of Hazardous And Harmful Drinking. London: National Institute for Health and Clinical Excellence, 2010.

25. NHS Confederation \& RCP. Too Much of The Hard Stuff: What Alcohol Costs the NHS. 2010. http://www.nhsconfed.org/Publications/Documents/ Briefing_193_Alcohol costs the NHS.pdf (accessed 15 Jul 2011).

26. Department of Health. Signs For Improvement-Commissioning Intervention To Reduce Alcohol Related Harm. 2009. http://www.dh.gov.uk/prod_consum_dh/ groups/dh_digitalassets/documents/digitalasset/dh_104854.pdf (accessed 15 Jul 2011).

27. Huntley JS, Patton R, Touquet R. Attitudes towards alcohol of emergency department doctors trained in the detection of alcohol misuse. Ann $R$ Coll Surg Engl 2004:86:329-33

28. Hoskins R, Salmon D, Binks S, et al. A study exploring drug use and management of patients presenting to an inner city emergency department. Accid Emerg Nurs 2005; 13:147-53.

29. Patton R, Strang J, Birtles C, et al. Alcohol: a missed opportunity. A survey of all accident and emergency departments in England. Emerg Med J 2007;24 $529-31$ 


\title{
EM]
}

\section{What is the burden of alcohol-related injuries in an inner city emergency department?}

\author{
Rebecca Hoskins and Jonathan Benger \\ Emerg Med J published online June 20, 2012 \\ doi: 10.1136/emermed-2011-200510
}

Updated information and services can be found at:

http://emj.bmj.com/content/early/2012/05/30/emermed-2011-200510.full.html

These include:

References This article cites 16 articles, 5 of which can be accessed free at: http://emj.bmj.com/content/early/2012/05/30/emermed-2011-200510.full.html\#ref-list-1

$\mathbf{P}<\mathbf{P} \quad$ Published online June 20, 2012 in advance of the print journal.

Email alerting Receive free email alerts when new articles cite this article. Sign up in service the box at the top right corner of the online article.

Topic Articles on similar topics can be found in the following collections

Collections

Press releases (14 articles)

Alcohol (26 articles)

Notes

Advance online articles have been peer reviewed, accepted for publication, edited and typeset, but have not not yet appeared in the paper journal. Advance online articles are citable and establish publication priority; they are indexed by PubMed from initial publication. Citations to Advance online articles must include the digital object identifier (DOIs) and date of initial publication.

To request permissions go to:

http://group.bmj.com/group/rights-licensing/permissions

To order reprints go to:

http://journals.bmj.com/cgi/reprintform

To subscribe to BMJ go to:

http://group.bmj.com/subscribe/ 